\title{
Bioaugmentation of Sewage Sludge with Trametes versicolor in Solid- Phase Biopiles Produces Degradation of Pharmaceuticals and Affects Microbial Communities
}

\author{
Carlos E. Rodríguez-Rodríguez, ${ }^{* \dagger, \dagger}$ Aleksandra Jelić, ${ }^{\S}$ M. Alcina Pereira," Diana Z. Sousa," \\ Mira Petrović, ${ }^{\perp, \#}$ M. Madalena Alves, $"$ Damià Barceló, ${ }^{\S, \#}$ Glòria Caminal, ${ }^{\dagger}$ and Teresa Vicent ${ }^{\nabla}$ \\ ${ }^{\dagger}$ Unitat Asociada de Biocatàlisi Aplicada IQAC-CSIC. Escola d’Enginyeria, Universitat Autònoma de Barcelona (UAB), 08193 \\ Bellaterra, Barcelona, Spain \\ ${ }^{\ddagger}$ Centro de Investigación en Contaminación Ambiental, Universidad de Costa Rica (UCR), 2060 San José, Costa Rica \\ ${ }^{\S}$ Department of Environmental Chemistry, Institute of Environmental Assessment and Water Research (IDAEA), Spanish Council for \\ Scientific Research (CSIC), Jordi Girona 18-26, 08034 Barcelona, Spain \\ "IBB-Institute for Biotechnology and Bioengineering, Centre of Biological Engineering, University of Minho, 4710-057 Braga, \\ Portugal \\ ${ }^{\perp}$ Institució Catalana de Reserca i Estudis Avançats (ICREA), Passeig Lluis Companys 23, 80010 Barcelona, Spain \\ ${ }^{\#}$ Catalan Institute for Water Research (ICRA), H2O Building, Scientific and Technological Park of the University of Girona 101, \\ E-17003 Girona, Spain \\ ${ }^{\nabla}$ Departament d'Enginyeria Química, Escola d'Enginyeria, UAB, 08193 Bellaterra, Barcelona, Spain
}

Supporting Information

ABSTRACT: The use of sludge (biosolids) in land application may contribute to the spread of organic micropollutants as wastewater treatments do not completely remove these compounds. Therefore, the development of alternative strategies for sludge treatment is a matter of recent concern. The elimination of pharmaceuticals at pre-existent concentrations from sewage sludge was assessed, for the first time, in nonsterile biopiles by means of fungal bioaugmentation with Trametes versicolor (BTV-systems) and compared with the effect of autochthonous microbiota (NB-systems). The competition between the autochthonous fungal/bacterial communities and $T$. versicolor was studied using denaturing gradient gel electrophoresis (DGGE) and the cloning/ sequencing approach. An inhibitory effect exerted by $T$. versicolor over bacterial populations was suggested. However, after 21 days, T. versicolor was no longer the main taxon in the

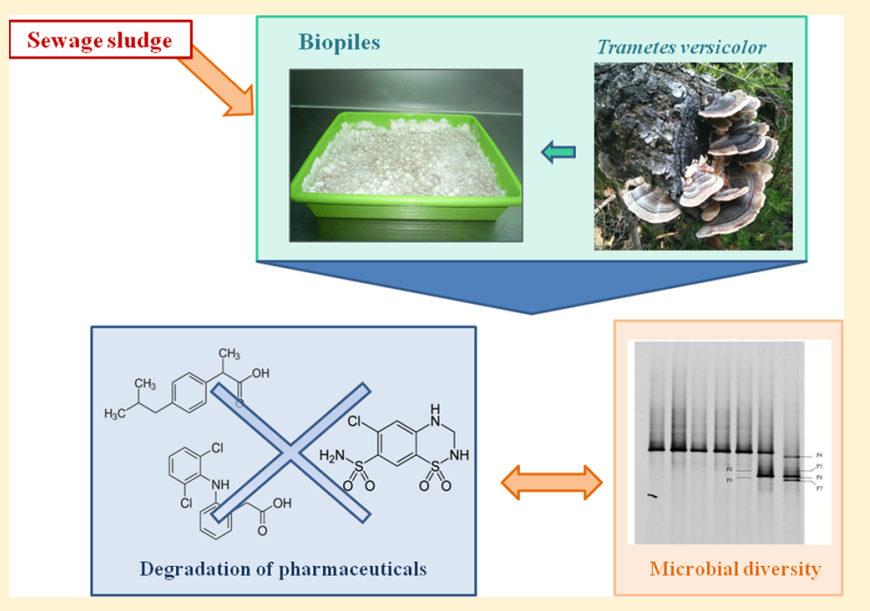
fungal communities. The elimination profiles revealed an enhanced removal of atorvastatin-diclofenac-hydrochlorothiazide (during the whole treatment) and ranitidine-fenofibrate (at short periods) in the BTV biopiles in respect to NB biopiles, coincident with the presence of the fungus. For ibuprofen-clarithromycin-furosemide, the elimination profiles were similar irrespective of the system, and with carbamazepine no significant degradation was obtained. The results suggest that a fungal treatment with $T$. versicolor could be a promising process for the remediation of some pharmaceuticals in complex matrices such as biosolids.

\section{INTRODUCTION}

Pharmaceuticals comprise a diverse group of therapeutic compounds intended to improve health. The expanding world population, discovery of new drugs, and the use of cheaper generic agents are some of the reasons of the increasing use of pharmaceuticals. After human or veterinary consumption, pharmaceuticals reach urban aquatic environments, ending up in the wastewater treatment plants (WWTPs), which are usually regarded as the main points of discharge of pharmaceuticals into ecosystems. ${ }^{2}$ The recent concern on the occurrence and fate of pharmaceuticals in WWTPs and receiving surface waters and its subsequent monitoring have revealed the incapability of conventional wastewater treatments

Received: May 4, 2012

Revised: September 14, 2012

Accepted: October 2, 2012

Published: October 2, 2012 
to completely remove and thus prevent the entrance of these emerging pollutants into the environment. ${ }^{3,4}$ Although a fraction of the pharmaceuticals is removed from the aqueous phase of wastewater, important amounts remain adsorbed in the solid sludge, which for some compounds represents the main removal route during wastewater treatment. ${ }^{5}$ The sewage sludge constitutes a final residue in the WWTPs. The application of sludge (biosolids) in agriculture as soil amendment or in landfills is one of the most applied solutions for their disposal. ${ }^{6,7}$ However, legislation on biosolids only focuses on heavy metals and bacterial pathogens and more recently in some organic pollutants such as polychlorinated biphenyls, polycyclic aromatic hydrocarbons, dioxins, and halogenated compounds, ${ }^{8}$ without considering pharmaceuticals and other groups of micropollutants. Therefore, biosolids become another important input of pharmaceuticals to the environment, ${ }^{9}$ as their application results not only in the direct spread of the therapeutic drugs on soils but eventually in surface- and groundwater after runoff by rain. ${ }^{10}$

Nowadays, although the potential impact of pharmaceuticals in the environment is little understood, studies have emerged showing their potential deleterious impact on wildlife and possible effects on ecosystems, including acute and chronic toxicity, inhibition of natural microbial processes, and spread of resistance to antibiotics, among others. ${ }^{3,11-14}$ Moreover, the potential risk of toxicity due to mixtures, as those found in sludge, has gained more attention. ${ }^{3}$

In this context, the search of alternative approaches, especially eco-friendly treatments for the elimination of organic pollutants from sludge, is a matter of great interest. Bioremediation has appeared as an advantageous cleanup technique of xenobiotics from the environment, and bioaugmentation, the addition of pregrown microorganisms to enhance the degradation of unwanted compounds, is a promising approach of bioremediation. ${ }^{15}$ White-rot fungi (WRF) comprise a group of extensively studied organisms capable to degrade a wide range of pollutants by means of their extracellular ligninolytic enzymes and intracellular enzymatic complexes. The degrading versatility of WRF has been reviewed elsewhere ${ }^{16-18}$ and includes the transformation of pharmaceuticals in defined liquid media, ${ }^{19,20}$ however their use in bioaugmentation processes has been reduced due to their limited colonization potential. ${ }^{21}$ Most of the research on degradation by WRF has been performed in defined media or sterile matrices and bioaugmentation in solid phase is circumscribed to few reports in soil for the elimination of $\mathrm{PAHs}^{22-25}$ or pentachlorophenol. ${ }^{26-28}$ Moreover, bioaugmentation of sewage sludge with single microorganisms has only been tested with bacteria ${ }^{29}$ and, as far as the authors know, never for the treatment of emerging pollutants.

In previous works, we demonstrated the proper colonization of sewage sludge by the WRF Trametes versicolor and its ability to remove pharmaceuticals (both spiked and pre-existent) from this complex matrix in sterile conditions. ${ }^{30,31}$ The present work focuses in the next step, which deals with the challenge of applying the fungus in nonsterile sludge, where the indigenous microbiota may counteract the fungal growth and its degrading ability.

This article describes a bioremediation process that employs T. versicolor as a bioaugmentation agent for the removal of preexistent pharmaceuticals from sewage sludge. The dynamics of the fungal and bacterial communities during the process was also monitored to understand how indigenous microbiota is affected by the inoculation of an external fungus.

\section{MATERIALS AND METHODS}

Pharmaceutical Standards. All of the pharmaceutical and the corresponding isotopically labeled standards were of high purity grade $(>90 \%)$. Detailed information on the providers of the analytical standards can be found in S1 Chemicals of the Supporting Information. The individual standard solutions as well as isotopically labeled standard solutions were prepared according to Gros et al. ${ }^{32}$ The solvents, HPLC grade methanol, acetonitrile, water (Lichrosolv), and formic acid (98\%) were provided by Merck (Darmstadt, Germany).

Sewage Sludge and Bulking Material. Dry sewage sludge was obtained from the wastewater treatment plant of El Prat de Llobregat. The plant is located near Barcelona, Spain, and has a total treatment capacity of two million equivalent inhabitants. It is a typical biological activated sludge plant with sludge anaerobic digestion and thermal drying. Sludge employed in the experiments was obtained from the final stage of processing, that is, after thermal drying ( $\sim 10 \%$ water content). The wheat-straw pellets (WSP, ATEA Praha s.r.o., Czech Republic) used both as bulking material and lignocellulosic substrate for fungal growth in bioaugmentation experiments were kindly provided by Č. Novotný.

Solid-Phase Bioremediation Treatments. Two treatments were carried out to evaluate the efficiency of pharmaceuticals degradation in sewage sludge and the dynamics of microbial communities: (i) nonbioaugmented treatment (addition of WSP, moisture and regulated temperature; NB) and (ii) bioaugmentation with the fungus T. versicolor (addition of pregrown fungus on WSP; BTV). To compare the removal performance of $T$. versicolor alone, a sterilized system inoculated with the fungus was included (CTV).

Microcosm Description. Sludge biopile systems with a total solid dry weight (DW) of approximately $368 \mathrm{~g}$ were prepared in plastic trays with a $20 \times 27 \mathrm{~cm}$ surface and a height of $6 \mathrm{~cm}$. The nonbioaugmented sludge contained 38\% WSP as amendment ( $w / w$, dry basis), which were hydrated (1:2 ratio, $\mathrm{w} / \mathrm{v}$ ) prior mixing with the sludge. The bioaugmented sludge contained $38 \%(\mathrm{w} / \mathrm{w}$, dry basis) T. versicolor inoculum grown on WSP. The strain T. versicolor ATCC 42530 was acquired from the American Type Culture Collection. Inocula were prepared by the addition of a blended mycelium suspension ${ }^{33}$ to WSP ( $0.65 \mathrm{~mL}$ per gram of dry WSP) and pregrowing for 7 $\mathrm{d}$ at $25^{\circ} \mathrm{C}$. WSP were hydrated $(1: 2$ ratio, w/v) prior mycelium addition. Both conditions were done in triplicate biopiles. Duplicate sterilized biopiles inoculated with $T$. versicolor were prepared with autoclaved sludge $\left(121{ }^{\circ} \mathrm{C}\right.$ for $\left.30 \mathrm{~min}\right)$ as described for bioaugmented sludge. In every case, biopiles were incubated for up to $42 \mathrm{~d}$ at $25{ }^{\circ} \mathrm{C}$, periodically homogenized and moisturized, and sampled for different analyses on times 0 , $3,6,10,14,21,28,35$, and $42 \mathrm{~d}$; time-points are indicated on the text as $\mathrm{tX}$, where $\mathrm{X}$ corresponds to the day of sampling.

Analytical Procedures. Sample Preparation and Analysis of Pharmaceuticals. The preparation of the solid samples for the analysis of selected pharmaceuticals was performed according to Jelic et al. ${ }^{34}$ In brief, the samples were freezedried and ground, and extracted using an accelerated solvent extraction system (ASE) (Dionex ASE 200, Dionex; Sunnyvale, CA). The concentrated extracts were diluted in HPLC water (methanol content $<5 \%$ ), and processed by solid phase extraction using Oasis HLB (200 mg, $6 \mathrm{~mL}$ ) cartridges 
(Waters, Milford, MA) at neutral $\mathrm{pH}$. Instrumental analysis of the samples was performed by high performance liquid chromatography coupled to tandem mass spectrometry (HPLC-MS/MS). HPLC analysis was performed using Symbiosis Pico (SP104.002, Spark, Holland), equipped with an autosampler and connected in series with a 4000 QTRAP Hybrid Triple Quadrupole - Linear Ion Trap mass spectrometer equipped with a Turbo Ion Spray source (Applied Biosystems-Sciex, Foster City, CA, USA). Chromatographic separation was achieved with a Purospher Star RP-18 endcapped column $(125 \mathrm{~mm} \times 2.0 \mathrm{~mm}$, particle size $5 \mu \mathrm{m})$ preceded by a $\mathrm{C}_{18}$ guard column $(4 \mathrm{~mm} \times 4 \mathrm{~mm}$, particle size 5 $\mu \mathrm{m})$, both supplied by Merck (Darmstadt, Germany). The concentrations of pharmaceuticals were determined using a previously developed multiresidual methodology for analysis of pharmaceuticals. ${ }^{32}$ The internal standard calibration approach was used for quantification. To determine the recoveries, three samples of each matrix were spiked with a standard mixture of target analytes. The recoveries ranged from 42 to $123 \%$ (RSD < $15 \%)$. The instrumental intraday precision ranged from 2 to $13 \%$, for five injections of a $50 \mathrm{ng} \mathrm{mL}{ }^{-1}$ standard mixture. The method quantification limits (MQL), calculated as ten times signal-to-noise, ranged from 0.5 to $7.0 \mathrm{ng} \mathrm{g}^{-1} \mathrm{DW}$, and they are included for the complete list of analyzed compounds (43 drugs) as seen in Table S1 of the Supporting Information.

Ergosterol quantification. Ergosterol was measured in homogeneously mixed samples of solid-phase cultures. Extraction and quantification were performed as previously described. ${ }^{30}$ Ergosterol content was expressed as milligrams per gram of solid DW.

Laccase Activity. Laccase was extracted from solid samples according to Rodríguez-Rodríguez et al. ${ }^{30}$ Activity was measured using a modified version of the method for the determination of manganese peroxidase, ${ }^{35}$ using 2,6-dimethoxyphenol (DMP) as the substrate (extinction coefficient: 24800 $\left.\mathrm{M}^{-1} \mathrm{~cm}^{-1}\right) .{ }^{36}$ Results were expressed as activity units (U) per gram of solid DW. One $U$ was defined as the number of micromoles of DMP oxidized per min.

ND24 Test. A test based on naproxen degradation, previously defined by Rodríguez-Rodríguez et al. ${ }^{37}$ was employed to monitor the degrading ability of $T$. versicolor throughout the treatment. The test indicates the percentage of degradation of spiked naproxen in $24 \mathrm{~h}$ by comparing the remaining naproxen concentrations in active cultures to those in heat-killed controls.

Microbial Community Analysis. Sampling and DNA Extraction. Homogenized samples were withdrawn from the biopiles over a period of $42 \mathrm{~d}$ and stored at $-20{ }^{\circ} \mathrm{C}$. Total genomic DNA was extracted from approximately $0.4 \mathrm{~g}$ samples using the Fast DNA Spin kit for soil (MP Biomedicals, USA) according to the manufacturer's instructions. Extracted DNA was maintained at $-20{ }^{\circ} \mathrm{C}$ and used as a template for PCR amplification.

PCR Amplification. Bacterial 16S rRNA genes and internal transcribed spacer (ITS) regions of fungal rRNA genes were amplified from total genomic DNA using a Taq polymerase kit (Invitrogen, Carlsbad, CA, USA). PCR amplification was performed in reaction mixture $(50 \mu \mathrm{L})$ containing $20 \mathrm{mM}$ Tris- $\mathrm{HCl}$ (pH 8.4), $50 \mathrm{mM} \mathrm{KCl,} 3 \mathrm{mM} \mathrm{MgCl}, 200 \mu \mathrm{M}$ each of the four deoxynucleoside triphosphates (dNTP), 1.25 U Taq polymerase, $200 \mathrm{nM}$ each primer, and $1 \mu \mathrm{L}$ of properly diluted template DNA. All primers employed were synthesized by Invitrogen. Complete bacterial 16S rRNA genes were amplified for cloning and sequencing by using the forward primer Bact27- f (5'-GTT TGA TCC TGG CTC AG-3') and the universal reverse primer Uni1492-r (5'-CGG CTA CCT TGT TAC GAC $\left.-3^{\prime}\right) .{ }^{38}$ The thermocycling program was: $95^{\circ} \mathrm{C}$ for $2 \mathrm{~min}$; $95{ }^{\circ} \mathrm{C}$ for $30 \mathrm{~s}, 52{ }^{\circ} \mathrm{C}$ for $40 \mathrm{~s}$ and $72{ }^{\circ} \mathrm{C}$ for $90 \mathrm{~s}$ ( 25 cycles), and $72{ }^{\circ} \mathrm{C}$ for $5 \mathrm{~min}$. In the case of fungal ITS regions the forward primer ITS1F ( $5^{\prime}$-CTT GGT CAT TTA GAG GAA GTA A- $\left.3^{\prime}\right)^{39}$ and the reverse primer ITS4 (5'-TCC TCC GCT TAT TGA TAT GC- $\left.3^{\prime}\right)^{40}$ were employed. The thermocycling program was as described above but with an annealing temperature of $55{ }^{\circ} \mathrm{C}$. For DGGE analysis, PCR products were generated using bacterial $16 \mathrm{~S}$ rRNA gene primers U968-f (5'-ACC GCG AAG AAC CTT AC-3') and L1401-r (5'-CGG TGT GTA CAA GAC CC- $\left.3^{\prime}\right)^{41}$ for amplification of the V6V8 bacterial region, and the fungal rRNA primers ITS1F and ITS2 (5'-GCT GCG TTC TTC ATC GAT GC-3'). ${ }^{40}$ A 40base GC clamp (CGC CCG GGG CGC GCC CCG GGC GGG GCG GGG GCA CGG GGG G) was attached to the primers U968-f and ITS1F at the $5^{\prime}$ end. The thermocycling program was as described above but with 35 cycles, an annealing temperature of $56{ }^{\circ} \mathrm{C}$ for bacterial primers and elongation time of $1 \mathrm{~min}$ for fungal primers. The size and amount of PCR products was estimated by electrophoresis in $1 \%$ agarose gels $(\mathrm{w} / \mathrm{v})$ using a DNA marker and ethidium bromide staining.

DGGE Analysis. DGGE analysis of the PCR products was performed with a DCode system (Bio-Rad, Hercules, CA, USA). Gels containing $8 \%(\mathrm{w} / \mathrm{v})$ polyacrilamide (37.5:1 acrylamide/bis-acrylamide) with a denaturing gradient of 30$60 \%$ for bacteria and $20-60 \%$ for fungi were employed. The $100 \%$ denaturant corresponded to $7 \mathrm{M}$ urea and $40 \%(\mathrm{v} / \mathrm{v})$ formamide. Electrophoresis was performed for $16 \mathrm{~h}$ at $85 \mathrm{~V}$ in $0.5 \times$ TAE buffer at $60{ }^{\circ} \mathrm{C}$. Gels were then stained with silver nitrate and scanned in an Epson Perfection V750 PRO (Epson, USA).

Cloning and Sequencing. Fragments previously amplified by PCR using the primers Bact27-f/Uni1492-r and ITS1F/ ITS4 were purified by means of the PCR cleanup kit NucleoSpin Extract II (Macherey-Nagel, Germany). The fragments were then incorporated into a pGEM-T vector using the pGEM Easy Vector Systems kit (Promega, Madison, WI, USA). The vector was employed in the transformation of Escherichia coli competent cells E. cloni 10G Electrocompetent Cells (Lucigen Corporation) according to the manufacturer's instructions. Positive transformants were selected after growth in LB medium supplemented with ampicillin. After PCR amplification with U968GC-f/L1401-r or ITS1FGC/ITS2, clones were screened in DGGE by means of comparing with the corresponding band-patterns of the sludge. Those clones matching different bands in the total community profile were selected, and their inserts were amplified by PCR using the pGEM-T vector-targeted sequencing primers Sp6 (5'-GAT TTA GGT GAC ACT ATA G-3') and T7 (5'-TAA TAC GAC TCA CTA TAG GG-3') (Promega), purified (NucleoSpin Extract II kit) and subjected to DNA sequence analysis. Inserts were bidirectionally sequenced with the primers Sp6/T7 at Eurofins MWG Operon (Ebersberg, Germany).

Phylogenetic Analysis. Partial sequences were assembled using the CAP application included in the BioEdit v7.0.9 software package. ${ }^{42}$ Similarity searches for the assembled sequences were performed using the NCBI Blast search program within the GenBank database (http://www.ncbi.nlm. nih.gov/blast/). ${ }^{43}$ 


\section{RESULTS}

Parameters of Growth and Activity in Bioaugmentation with $T$. versicolor. Solid-phase biopile systems were employed to study the bioaugmentation of sewage sludge with $T$. versicolor for the removal of pharmaceuticals. The lignocellulosic WSP employed in the biopiles acted both as a substrate ( $\mathrm{C}$ and $\mathrm{N}$ source) for fungal growth and a carrier of $T$. versicolor. Preliminary studies revealed that the preparation of the biopiles as described by Rodríguez-Rodríguez et al. ${ }^{31}$ in sterile conditions could not support the colonization of the nonsterile sludge by the fungus (data not shown); therefore, a reduction in the initial moisture (aprox. from 2.6 to $2.2 \mathrm{~g}$ water per $\mathrm{g}$ DW) of the system was applied to favor the colonization of the matrix in the BTV biopiles. Figure 1 shows the results of

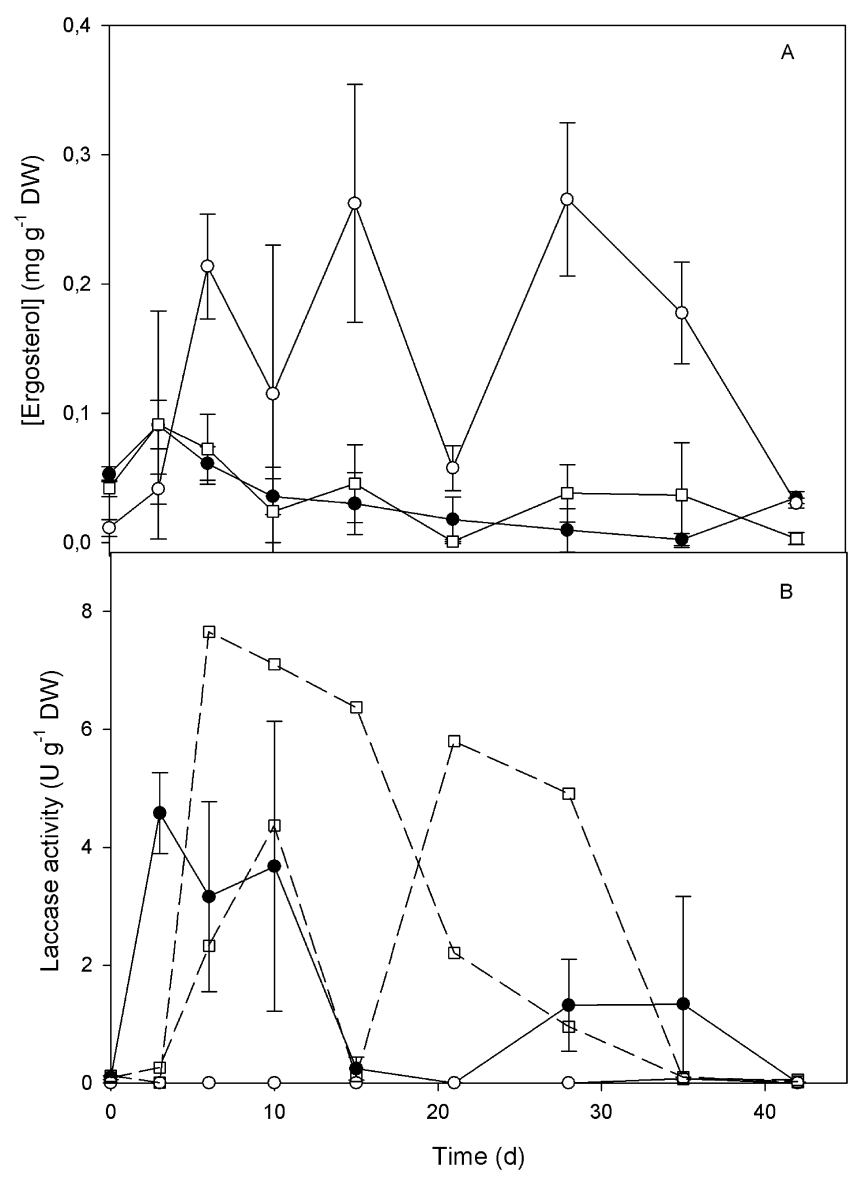

Figure 1. Profiles of ergosterol (A) and laccase activity (B) over time in the bioremediation treatments of sewage sludge: NB (O), BTV $(\bullet)$, CTV ( $\square$ ). Values plotted are the means \pm standard deviation (SD) for triplicate biopiles, except for CTV in B (two replicates individually plotted).

ergosterol, employed as an indicator of fungal biomass, ${ }^{44}$ and laccase, as an indicator of extracellular enzymatic activity of $T$. versicolor, directly related to the oxidative potential of the system and involved in the degradation of several polutants. ${ }^{16}$ BTV and CTV presented similar ergosterol profiles (part A of Figure 1), with maximum values $\left(0.091 \mathrm{mg} \mathrm{g}^{-1} \mathrm{DW}\right.$ and 0.092 $\mathrm{mg} \mathrm{g}^{-1} \mathrm{DW}$, respectively) in the first days of the treatment. The profile of NB biopiles was more oscillatory, though values were usually higher than those shown by BTV and CTV biopiles after $6 \mathrm{~d}$. However, by the end of the process, ergosterol in the NB biopiles matched the final value of the BTV biopiles.
Laccase activity profile of BTV systems revealed high levels in the first $10 \mathrm{~d}$ (maximum $4.58 \mathrm{U} \mathrm{g}^{-1} \mathrm{DW}$ at day 3), with a posterior decrease and a new raise between $\mathrm{t} 28$ and $\mathrm{t} 35$ (part $\mathrm{B}$ of Figure 1). Results were similar, though higher, for the replicates of the CTV, with peak values of around $7.66 \mathrm{U} \mathrm{g}^{-1}$ DW, but the expression of the enzymatic activity started later in this case. No activity was detected in the NB biopiles, except at $\mathrm{t} 35$ (0.08 $\left.\mathrm{U} \mathrm{g}^{-1} \mathrm{DW}\right)$, at a negligible value compared to the other systems. The ND24 test, employed as an indicator of degrading ability of $T$. versicolor, presented degradation values over $10 \%$ only at t6 in the BTV biopiles (ND24 values are shown in Table S2 of the Supporting Information).

Removal of Pharmaceuticals from Sludge. From 43 pharmaceuticals analyzed, 9 were detected in the sewage sludge; their elimination profiles are shown in Figure 2. The most abundant therapeutic agents were the analgesic/antiinflammatory compounds ibuprofen and diclofenac (Table 1). Removal of ibuprofen after $42 \mathrm{~d}$ was similar in all the bioremediation treatments, ranging from $55.9 \%$ to $61.0 \%$ (Table 1). Contrary, diclofenac was better degraded in the BTV (54.0\%) and CTV (60.5\%) biopiles, against only $22.0 \%$ in the NB systems.

Two lipid regulators, fenofibrate and atorvastatin, were detected. The former was easily removed from the sludge, as it completely disappeared at the end of the process, with or without bioaugmentation. However, atorvastatin was more efficiently removed in the BTV (65.4\%) and CTV (70.4\%) biopiles, whereas elimination exclusively due to indigenous microbiota reached $48.4 \%$.

In the cases of the histamine $\mathrm{H} 2$-receptor antagonist ranitidine and the diuretic furosemide, the degradation was complete in all the systems, by the end of the treatment for the former, and by 110 for the latter. Similarly, for the antibiotic clarithromycin the removal was the same irrespective of the process, between $81.7 \%$ and $84.5 \%$ after $42 \mathrm{~d}$. The other diuretic, hydrochlorothiazide, showed a slightly better removal in the biopiles with T. versicolor $(65.4 \%$ in BTV and $62.7 \%$ in CTV) than the NB biopiles (55.3\%). Finally, carbamazepine, detected at an initial concentration of $10.5 \mathrm{ng} \mathrm{g}^{-1}( \pm 0.7)$ was the only drug that remained unchanged regardless of the applied treatment.

Dynamics and Characterization of Fungal and Bacterial Communities. DGGE profiles were obtained for samples of the triplicate BTV and NB biopiles. Profiles in the replicates were highly similar for bacterial and fungal communities, and thus only the results of one of the replicates are included. A more detailed analysis of the structure of the microbial communities was also performed by cloning and sequencing analyses of the 16S rRNA gene and ITS regions of fungal rRNA gene Figure 3.

DGGE profiles of fungal communities are shown in parts $A$ and $\mathrm{B}$ of Figure 3 . In the NB biopiles, bands were absent at t0 and only one band weakly appeared at t6; after t10 a higher fungal diversity was observed, with several bands that were present up to 42 (part A of Figure 3). Sample TV corresponds to the product amplified from the genomic DNA of a pure culture of T. versicolor. In the BTV biopiles this band prevailed alone until t 10 , and shared predominance in the community on $\mathrm{t} 21$; however, it disappeared by the end of the treatment at $\mathrm{t} 42$, when the predominant bands included those also found in the NB biopiles (part B of Figure 3). Fungal sequences corresponding to bands F1, F5 and F8 showed high similarity to Scopulariopsis brevicaulis, a common soil saprophyte. ${ }^{45}$ These 



Figure 2. Time-course removal of detected pharmaceuticals in the sludge biopiles during a $42 \mathrm{~d}$ bioremediation treatment: NB $(\mathbf{0})$, BTV $(O)$, and CTV $(\boldsymbol{\nabla})$. Values plotted are the means \pm SD for triplicate biopiles.

Table 1. Initial Concentration of Pharmaceuticals Detected in the Sewage Sludge and Degradation in Different Bioremediation Strategies

\begin{tabular}{|c|c|c|c|c|c|c|c|}
\hline \multirow[b]{2}{*}{ pharmaceutical } & \multirow[b]{2}{*}{ MQL (ng g $\left.{ }^{-1} \mathrm{DW}\right)$} & \multirow[b]{2}{*}{ recovery $(\%, n=3)$} & \multirow[b]{2}{*}{$\begin{array}{l}\text { initial concentration } \\
\text { (average) }\end{array}$} & \multirow[b]{2}{*}{$\begin{array}{l}\text { concentration range, t0 } \\
(\min -\max )\end{array}$} & \multicolumn{3}{|c|}{ degradation (\%, average) } \\
\hline & & & & & NB t42 & BTV t42 & CTV $\mathrm{t} 42$ \\
\hline fenofibrate & 1.8 & $55( \pm 13)$ & $13.7( \pm 1.8)$ & $12.0-15.6$ & 100 & 100 & 100 \\
\hline atorvastatin & 2.9 & $59( \pm 8.2)$ & $19.3( \pm 2.6)$ & $16.6-21.8$ & $48( \pm 10)$ & $65( \pm 10)$ & $70( \pm 12)$ \\
\hline hydrochlorothiazide & 2.6 & $87( \pm 14)$ & $10.8( \pm 1.7)$ & $9.4-12.6$ & $55( \pm 11)$ & $65( \pm 11)$ & $63( \pm 14)$ \\
\hline diclofenac & 3.6 & $67( \pm 7.3)$ & $53.6( \pm 4.8)$ & $48.4-57.6$ & $22( \pm 7)$ & $54( \pm 6)$ & $60( \pm 8)$ \\
\hline clarithromycin & 3.1 & $73( \pm 3.0)$ & $35.8( \pm 6.8)$ & $29.1-35.6$ & $85( \pm 15)$ & $82( \pm 14)$ & $84( \pm 17)$ \\
\hline ranitidine & 5.3 & $42( \pm 13)$ & $17.5( \pm 1.3)$ & $16.1-18.7$ & 100 & 100 & 100 \\
\hline carbamazepine & 1.0 & $121( \pm 11)$ & $10.5( \pm 0.7)$ & $9.9-11.2$ & & & $9( \pm 8)$ \\
\hline ibuprofen & 2.7 & $63( \pm 7.9)$ & $161.0( \pm 21.4)$ & $138-181$ & $61( \pm 9)$ & $56( \pm 9)$ & $60( \pm 11)$ \\
\hline furosemide & 3.9 & $42( \pm 8.7)$ & $23.4( \pm 1.7)$ & $22.3-25.3$ & 100 & 100 & 100 \\
\hline
\end{tabular}

bands developed with higher relative intensity in the samples from NB biopiles. Bands F2, F6, and F9, whose sequences matched with isolates of Gymnascella dankaliensis (99-100\% identity) were predominant in BTV systems. The sequences corresponding to the bands F3 and F7 were 91\% identical to the sequence of the cephalosporin-producer Acremonium chrysogenum, ${ }^{46}$ which appeared by $\mathrm{t} 42$ in both systems. At $\mathrm{t} 42$ but only in samples from BTV biopiles a band (F4) appeared, whose sequence has a $99 \%$ identity to an isolate of Gymnoascus sp. Both G. dankaliensis and Gymnoascus sp. are gymnoascaceous keratinophilic fungi usually found in soils. ${ }^{47}$ An additional clone not assigned in the DGGEs, with a gene sequence related to Cephaliophora tropica (98\% identity), a soil fungus, ${ }^{48}$ was obtained from the sample collected at $\mathrm{t} 21$ from the BTV biopiles. Overall results indicate that, with exception of $T$. versicolor, the fungal communities were similar in the $\mathrm{NB}$ and BTV treatments.

The DGGE profiles corresponding to the bacterial communities are presented in parts $\mathrm{C}$ and $\mathrm{D}$ of Figure 3. The NB biopiles showed higher diversity (in terms of number of bands) than the BTV biopiles. Several bands appeared after t0 and, although weak, some prevailed along the process. However, in the BTV biopiles the diversity observed at t0 disappeared during the treatment to produce the same pattern 
A

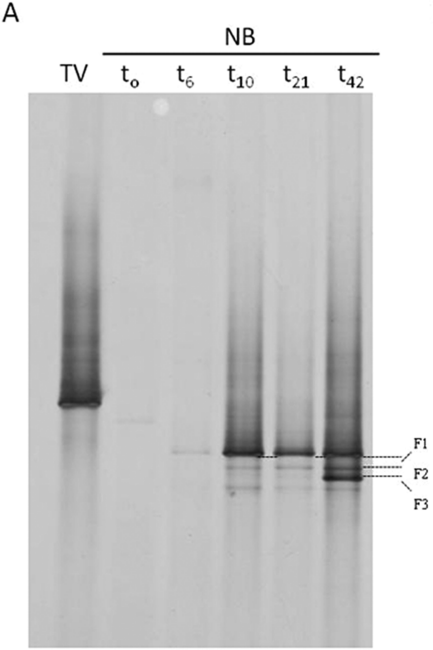

C

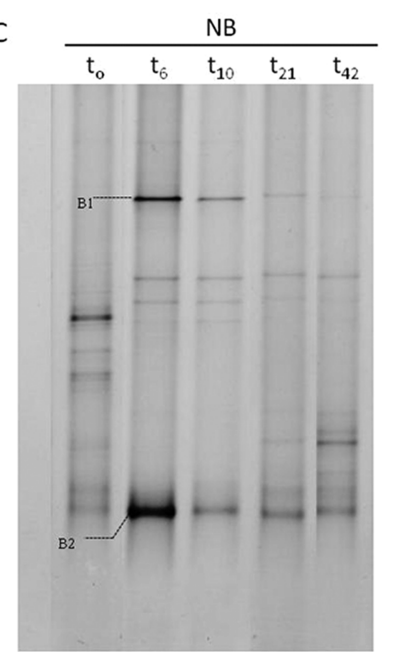

B
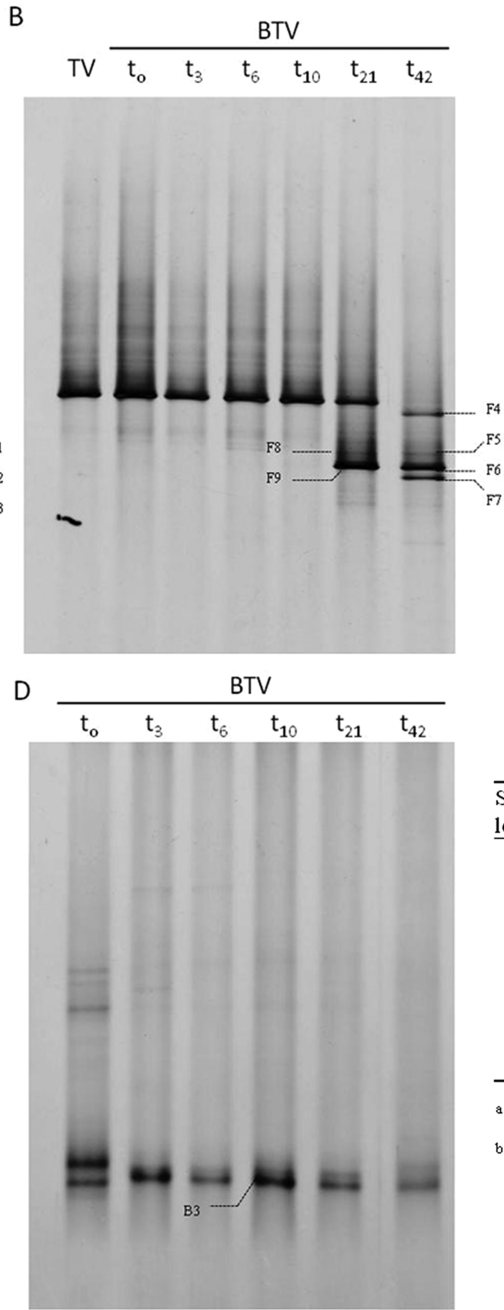

\begin{tabular}{llcc}
\hline $\begin{array}{l}\text { Sequence } \\
\text { length }\end{array}$ & $\begin{array}{l}\text { DGGE } \\
\text { band }\end{array}$ & Closest relative & $\begin{array}{c}\text { Identity } \\
(\%)\end{array}$ \\
\hline
\end{tabular}

$623 \quad$ F1/F5 Scopulariopsis brevicaulis isolate 2737 99

$624 \quad$ F2 Gymnascelladankaliensis strain NRRL1677 99

$543 \quad$ F3/F7 Acremoniumchrysogenum 91

$\begin{array}{llll}622 & \text { F4 Gymnoascussp. IFM } 59328 & 99\end{array}$

$624 \quad$ F6 Gymnascella dankaliensis strain NRRL1677 100

$624 \quad$ F8 Scopulariopsis brevicaulis isolate $2737 \quad 99$

$624 \quad$ F9 Gymnascella dankaliensis strain NRRL1677 99

506 assigned Cephaliophoratropica strain xsd08001 98

Closest organismsin GenBank

\begin{tabular}{|c|c|c|c|c|}
\hline $\begin{array}{l}\text { Sequence } \\
\text { length }\end{array}$ & $\begin{array}{l}\text { DGGE } \\
\text { band }\end{array}$ & Closest relative $^{a}$ & $\begin{array}{l}\text { Identity } \\
(\%)\end{array}$ & Order/Family ${ }^{b}$ \\
\hline 1478 & B1 & $\begin{array}{l}\text { Staphylococcusequorum } \\
\text { strain CTSP8 } \\
\text { Oceanobacillus sp. }\end{array}$ & 99 & $\begin{array}{l}\text { Bacillales/ } \\
\text { Staphylococcaceae }\end{array}$ \\
\hline 1486 & B2 & BSi20641 & 99 & Bacillales/Bacillaceae \\
\hline 1477 & $\begin{array}{l}\text { B3 } \\
\text { Not }\end{array}$ & Bacillussp. TH64 & 99 & Bacillales/B acillaceae \\
\hline 1476 & assigned & Bacilluscereus strain PPB6 & 100 & Bacillales/Bacillaceae \\
\hline
\end{tabular}

a Closest organisms in GenBank

${ }^{b}$ Classified using the RDP Naive Bayesian Classifier ${ }^{60}$

Figure 3. DGGE profiles of fungal PCR-amplified ITS fragments and bacterial PCR-amplified 16S rRNA gene fragments from sludge microcosms over a period of $42 \mathrm{~d}$. Fungal profiles: (A) Non-bioaugmented, NB and (B) bioaugmented, BTV; bacterial profiles: (C) non-bioaugmented, NB and (B) bioaugmented, BTV. TV corresponds to the amplified product from genomic DNA of a T. versicolor pure culture. Phylogenetic affiliation of the retrieved ITS or $16 \mathrm{~S}$ rRNA sequences and their corresponding band position in the DGGE profiles are shown on the right.

up to $\mathrm{t} 42$, which consisted of a predominant band that coexisted with the fungal population. The $16 \mathrm{~S}$ rRNA gene sequence corresponding to band B1 showed high identity (99\%) to an isolate of Staphylococcus equorum. This band was present in the NB biopiles but absent in the presence of $T$. versicolor. The two bands present throughout each of the processes, for example B2 and B3, have sequences that matched isolates belonging to the family Bacillaceae, Oceanobacillus sp. (99\% identity) and Bacillus sp. (99\% identity), which are genera that normally occur in wastewater treatment systems. ${ }^{49}$ An additional clone obtained from the sample collected at 110 from BTV biopiles, whose sequence was $100 \%$ identical to the $16 \mathrm{~S}$ rRNA gene sequence of Bacillus cereus, could not be assigned to a band in the DGGE profiles.

\section{DISCUSSION}

The present work addresses a fungal approach for the elimination of pharmaceuticals, a group of emerging pollutants, from thermally dried sewage sludge. The bioaugmentation with T. versicolor (BTV) was compared with the effect achieved with solely the indigenous microbiota of the sludge, which given its proliferation due to the use of WSP (observed in community analyses), could be considered as a biostimulation process (NB).

Although ergosterol has been previously applied to monitor fungal biomass production, results from NB biopiles (usually higher than BTV and CTV, contrary to what was expected given the size of the inoculum) suggest that it is not a suitable parameter to follow up the specific bioaugmentation with $T$. versicolor. This can be ascribed to the fact that ergosterol production (respect to total fungal biomass) is speciesspecific, ${ }^{44}$ and growth of indigenous fungi in NB biopiles with higher ergosterol production yields could surpass the amount due only to $T$. versicolor. However, laccase determination seemed to be a good parameter to monitor activity of $T$. versicolor in the bioaugmented systems as its production was negligible in NB biopiles. Although the laccase produced could participate in the elimination of some pharmaceuticals in the BTV biopiles, the pollutant transformation ability of $T$. versicolor is a complex process that, besides the extracellular lignin-modifying enzymes (such as laccase), also involves the intracellular cytochrome P450 system and probably additional mechanisms yet to be described. ${ }^{50,51}$ Similarly, results of the ND24 test in the BTV biopiles were much lower than those previously obtained under sterile conditions ${ }^{31,37}$ making the 
test of reduced applicability in this case due to the delay or inhibition in naproxen degradation by the interaction between $T$. versicolor and the microbiota.

Fungal DGGE profiles of BTV biopiles demonstrated that $T$. versicolor was able to survive in the sludge system (at least during half of the process), that is the fungus was not inhibited by autochthonous microbiota. Moreover, comparison of DGGE profiles of bacterial communities, on the contrary, revealed an inhibitory effect of $T$. versicolor over bacteria, as diversity shown in NB biopiles was reduced to one predominant band in the profile of BTV biopiles. This finding corresponds to a usually challenging key factor to overcome in bioaugmentation with fungi, since these microorganisms are commonly surpassed by bacteria in terms of colonization ability. The success of fungi in situations of competition with indigenous microbiota widely differs, ${ }^{23,52,53}$ in particular with respect to colonization of soil by T. versicolor. ${ }^{21,54,55}$ In the present case, the colonization could have been enhanced by the reduction of microbiota by the thermal treatment of the sludge in the WWTP and the application of low humidity conditions together with the use of the WSP as lignocellulosic substrate that favors the activity of WRF. The sporulated nature of most of the bacterial taxa identified is not strange given the origin of the sludge (thermally dried), and might correspond to survivors of that thermal process. Similarly, T. versicolor seemed to delay the colonization of the system by other fungi, which appeared as intense bands at $t 10$ and $t 21$ in DGGE profiles from NB and BTV biopiles, respectively. Those fungi can also correspond to survivors of the stabilization treatment or to recontamination organisms.

Degradation of all the pharmaceuticals found in this work has been reported from sterile sludge systems with $T$. versicolor in solid phase (except ranitidine and furosemide) ${ }^{31}$ and in bioslurry reactors (except fenofibrate and clarithromycin). ${ }^{56}$ The persistence of carbamazepine (widely known for its recalcitrance), which remained unchanged after the treatment, is remarkable under nonsterile conditions, as degradation values of $31 \%$ and $43 \%$ were obtained in sterile sludge systems with this fungus, ${ }^{31,56}$ which could suggest a counteracting effect of the indigenous biota on the degrading ability of the fungus toward this drug. Moreover, the degradation of this therapeutic drug has been evidenced by $T$. versicolor in liquid medium. ${ }^{57}$ Nonetheless, several analytical issues which point the appearance of a carbamazepine metabolite at the same retention time as the parent compound (during liquid phase degradation by T. versicolor) could indicate an underestimation in the degradation obtained in the biopiles (unpublished results).

For the removal of some pharmaceuticals no significant difference was obtained between BTV and NB biopiles, which indicates that the addition of the WSP may stimulate also the growth of indigenous microorganisms, as shown in NB-DGGE profiles. Likewise, degrading profiles of BTV and CTV systems are highly similar in most cases, which suggest that microbial interactions between the sludge microbiota and $T$. versicolor did not counteract the degrading ability of the fungus, a common issue when bioaugmentation agents are employed. In this respect, cooperation and antagonism phenomena have been described in microbiota-fungi interactions in pollutant degradation processes. ${ }^{52,53,58}$

In general, the fungal-mediated treatments (BTV and CTV) tended to result in higher degradation in shorter periods (by t10 or t21) than nonbioaugmented systems. Nonetheless, by the end of the process the NB biopiles equated the degradation accomplished in the former systems for many pharmaceuticals. That accelerated removal effect due to the presence of $T$. versicolor was coincident with its predominance in the systems during the first half of the treatment as demonstrated in the DGGE profiles. When comparing the removal of pharmaceuticals in NB and BTV biopiles, three kinds of profiles were observed: (i) compounds with higher removal in BTV biopiles, (ii) pharmaceuticals with similar removal regardless of the process, and (iii) drugs with negligible removal. Group (i) profiles include atorvastatin, diclofenac, and hydrochlorothiazole, in which the action of T. versicolor resulted in enhanced removal values throughout the process. In the case of fenofibrate and ranitidine an improved removal in the BTV biopiles was obtained during the first $21 \mathrm{~d}$ (complete elimination in the former) coincident with the period in which $T$. versicolor is the predominant taxon of the system, according to the results of the DGGEs of fungal communities, and more active according to the results from the ND24 test. However, a complete removal was achieved with both BTV and $\mathrm{NB}$ systems at the end of the process, indicating a slower but efficient degrading ability by the indigenous microbiota. Ibuprofen, clarithromycin, and furosemide comprise the group (ii) degrading profiles, in which no clear difference between the BTV and NB systems was found. Complete elimination of furosemide was fast (by t10), whereas in the case of ibuprofen and clarithromycin a steep elimination occurred in the first $10 \mathrm{~d}$ followed by a plateau ( $56-60 \%$ and $82-85 \%$, respectively). These results suggest that the fungal bioaugmentation process is not necessary for the removal of such pharmaceuticals, yet the presence of the fungus does not negatively affect the elimination of the drugs. Group (iii) profiles includes only carbamazepine, which in this case was not significantly removed as indicated above. Though this therapeutic drug has been widely considered as a nonbiodegradable compound in anaerobic digestion processes and WWTPs, ${ }^{2,59}$ its depletion has been demonstrated in sterile conditions with $T$. vesicolor in liquid phase and sludge. ${ }^{31,56,57}$

Summarizing, important potential in bioremediation of sludge was demonstrated by $T$. versicolor for the elimination of pharmaceuticals. Molecular and analytical results suggest a reduction in the activity of $T$. versicolor after $21 \mathrm{~d}$ of treatment. Therefore, additional strategies such as fungal reinoculation should be conducted in order to improve a potential bioremediation process. Likewise, important, although usually slower removal of pharmaceuticals by autochthonous microbiota should be further studied to consider the application of biostimulation or natural attenuation techniques as it has been described with partial success for some traditional environmental pollutants. Similarly, the degrading range of the fungus for the elimination of other emerging as well as traditional contaminants must be evaluated in these real conditions to estimate the reach of such process. The proposed treatment could be interesting from the applicability point of view, as the use of these composting-like technologies is widely extended in WWTPs. Nonetheless, a careful optimization of the incipient process here described should be performed (considering the search of cheaper lignocellulosic susbstrates and inoculum size among other aspects) before assessing an economic study to estimate the balance between the cost and the effects of the complete degradation spectrum of the fungus in the sludge. 


\section{ASSOCIATED CONTENT}

\section{S Supporting Information}

Details of analytical standards, list of analyzed compounds with MQLs, and results of ND24 test. This material is available free of charge via the Internet at http://pubs.acs.org.

\section{AUTHOR INFORMATION}

\section{Corresponding Author}

*Phone: +34 93 5814796, e-mail: CarlosEsteban.Rodriguez@ uab.cat.

Notes

The authors declare no competing financial interest.

\section{ACKNOWLEDGMENTS}

This work was supported by the Spanish Ministries of MMAMRM (project 010/PC08/3-04) and MICINN (projects CTQ2010-21776-C2-01 and AIB2010PT-00169). The cofunds from CRUP - Rectors Council of Portuguese Universities through the integrated Portuguese-Spanish action E51/11 are gratefully acknowledged. The Department of Chemical Engineering of the UAB is the Unit of Biochemical Engineering of the Xarxa de Referència en Biotecnologia de la Generalitat de Catalunya. C. Rodríguez-Rodríguez acknowledges UCR-CSIC for a predoctoral fellowship. This work was partly supported by the Generalitat de Catalunya (Consolidated Research Groups: Water and Soil Quality Unit 2009-SGR-965 and Biorem UAB 2009-SGR-656).

\section{REFERENCES}

(1) Daughton, C. G. Cradle-to-cradle stewardship of drugs for minimizing their environmental disposition while promoting human health. I. Rational for and avenues toward a green pharmacy. Environ. Health Perspect 2003, 111, 757-774.

(2) Radjenović, J.; Petrović, M.; Barceló, D. Fate and distribution of pharmaceuticals in wastewater and sewage sludge of the conventional activated sludge (CAS) and membrane bioreactor (MBR) treatment. Water Res. 2009, 43, 831-841.

(3) Kümmerer, K. The presence of pharmaceuticals in the environment due to man use - present knowledge and future challenges. J. Environ. Manage 2009, 90, 2354-2366.

(4) Ternes, T. A. Analytical methods for the determination of pharmaceuticals in aqueous environmental samples. TrAC Trends Anal. Chem. 2001, 20, 419-434.

(5) Golet, E. M.; Strehler, A.; Alder, A. C.; Giger, W. Determination of fluoroquinolone antibacterial agents in sewage sludge and sludgetreated soil using accelerated solvent extraction followed by solidphase extraction. Anal. Chem. 2002, 74, 5455-5462.

(6) La Guardia, M. J.; Hale, R. C.; Harvey, E.; Matteson Minor, T. Alkylphenol ethoxilate degradation products in land-applied sewage sludge (Biosolids). Environ. Sci. Technol. 2001, 35, 4798-4804.

(7) Ødegaard, H.; Paulsrud, B.; Karlsson, I. Wastewater sludge as a resource: sludge disposal strategies and corresponding treatment technologies aimed at sustainable handling of wastewater sludge. Water Sci. Technol. 2002, 46, 295-303.

(8) Working Document on Sludge, 3rd draft. ENV.\#.3./LM.; European Union: Brussels, Belgium, 2000; http://ec.europa.eu/environment/ waste/sludge/pdf/sludge_en.pdf.

(9) Kinney, C. A.; Furlong, E. T.; Zaugg, S. D.; Burkhardt, M. R.; Werner, S. L.; Cahill, J. D.; Jorgensen, G. R. Survey of organic wastewater contaminants in biosolids destined for land application. Environ. Sci. Technol. 2006, 40, 7207-7215.

(10) Santos, L.H.M.L.M.; Araújo, A. N.; Fachini, A.; Pena, A.; Delerue-Matos, C.; Montenegro, M.C.B.S.M. Ecotoxicological aspects related to the presence of pharmaceuticals in the aquatic environment. J. Hazard. Mater. 2010, 175, 45-95.
(11) Kidd, K. A.; Blanchfield, P. J.; Mills, K. H.; Palace, V. P.; Evans, R. E.; Lazorchak, J. M.; Flick, R. W. Collapase of a fish population after exposure to a synthetic estrogen. Proc. Natl. Acad. Sci. U.S.A. 2007, 104, 8897-8901.

(12) Kümmerer, K. Antibiotics in the aquatic environment - A review - Part 1. Chemosphere. 2009, 75, 417-434.

(13) Lange, R.; Hutchinson, T. H.; Croudace, C. P.; Siegmund, F.; Schweinfurth, H.; Hampe, P.; Panter, G. H.; Sumpter, J. P. Effects of the synthetic estrogen 17 alpha-ethinylestradiol on the life-cycle of the fathead minnow (Pimephales promelas). Environ. Toxicol. Chem. 2001, $20,1216-1227$.

(14) Oaks, J. L.; Gilbert, M.; Virani, M. Z.; Watson, R. T.; Meteyer, C. U.; Rideout, B. A.; Shivaprasad, H. L.; Ahmed, S.; Chaudhry, M. J.; Arshad, M.; Mahmood, S.; Ali, A.; Khan, A. A. Diclofenac residues as the cause of vulture population decline in Pakistan. Nature 2004, 427, 630-633.

(15) Tyagi, M.; da Fonseca, M. M. R.; de Carvalho, C. C. C. R. Bioaugmentation and biostimulation strategies to improve the effectiveness of bioremediation process. Biodegradation 2011, 22, $231-241$.

(16) Asgher, M.; Bhati, H. N.; Ashraf, M.; Legge, R. L. Recent developments in biodegradation of industrial pollutants by white rot fungi and their enzyme system. Biodegradation 2008, 19, 771-783.

(17) Gao, D.; Du, L.; Yang, J.; Wu, W. M.; Liang, H. A critical review on the application of white rot fungus to environmental pollution control. Crit. Rev. Biotechnol. 2010, 30, 70-77.

(18) Pointing, S. B. Feasibility of bioremediation by white-rot fungi. Appl. Microbiol. Biotechnol. 2001, 57, 20-33.

(19) Rodarte-Morales, A. I.; Feijoo, G.; Moreira, M. T.; Lema, J. M. Degradation of selected pharmaceutical and personal care products (PPCPs) by white-rot fungi. World J. Microbiol. Biotechnol. 2011, 27, $1839-1846$.

(20) Rodarte-Morales, A. I.; Feijoo, G.; Moreira, M. T.; Lema, J. M. Operation of stirred tank reactors (STRs) and fixed-bed reactors (FBRs) with free and immobilized Phanerochaete chrysosporium for the continuous removal of pharmaceutical compounds. Biochem. Eng. J. 2012, 66, 38-45.

(21) McErlean, C.; Marchant, R.; Banat, I. M. An evaluation of soil colonization potential of selected fungi and their production of ligninolytic enzymes for use in soil bioremediation applications. Antonie van Leeuwenhoek Int. J. Gen. Mol. Microbiol. 2006, 90, 147158.

(22) D’Annibale, A.; Ricci, M.; Leonardi, V.; Quarantino, D.; Mincione, E.; Petruccioli, M. Degradation of aromatic hydrocarbons by white-rot fungi in a historically contaminated soil. Biotechnol. Bioeng. 2005, 90, 723-731.

(23) Federici, E.; Leonardi, V.; Giubilei, M. A.; Quarantino, D.; Spaccapelo, R.; D'Annibale, A.; Petruccioli, M. Addition of allochthonous fungi to a historically contaminated soil affects both remediation efficiency and bacterial diversity. Appl. Microbiol. Biotechnol. 2007, 77, 203-211.

(24) Hestbjerg, H.; Arentsen Willumsen, P.; Christensen, M.; Andersen, O.; Suhr Jacobsen, C. Bioaugmentation of tar-contaminated soils under field conditions using Pleurotus ostreatus refuse from commercial mushroom production. Environ. Toxicil. Chem. 2003, 22, $692-698$.

(25) McFarland, M. J.; Qui, X. J. Removal of benzo(a)pyrene in soil composting systems amended with the white rot fungus Phanerochaete chrysosporium. J. Hazard. Mater. 1995, 42, 61-70.

(26) Cea, M.; Jorquera, M.; Rubilar, O.; Langer, H.; Tortella, G.; Diez, M. C. Bioremediation of soil contaminated with pentachlorophenol by Anthracophyllum discolor and its effect on soil microbial community. J. Hazard. Mater. 2010, 181, 315-323.

(27) Lamar, R. T.; Evans, J. W. Solid-phase treatment of a pentachlorophenol-contaminated soil using lignin-degrading fungi. Environ. Sci. Technol. 1993, 27, 2566-2571.

(28) Walter, M.; Boys-Wilson, K.; Boul, L.; Ford, C.; McFadden, D.; Chong, B.; Pinfold, J. Field-scale bioremediation of pentachlorophenol by Trametes versicolor. Int. Biodeter. Biodegr. 2005, 56, 51-57. 
(29) Boon, N.; Goris, J.; de Vos, P.; Verstraete, W.; Top, E. M. Bioaugmentation of activated sludge by an indigenous 3-chloroanilinedegrading Comamonas testosteroni strain, I2gfp. Appl. Environ. Microbiol. 2000, 66, 2906-2913.

(30) Rodríguez-Rodríguez, C. E.; Marco-Urrea, E.; Caminal, G. Degradation of naproxen and carbamazepine in spiked sludge by slurry and solid-phase Trametes versicolor systems. Bioresour. Technol. 2010, 101, 2259-2266.

(31) Rodríguez-Rodríguez, C. E.; Jelić, A.; Llorca, M.; Farré, M.; Caminal, G.; Petrović, M.; Barceló, D.; Vicent, T. Solid-phase treatment with the fungus Trametes versicolor substantially reduces pharmaceutical concentrations and toxicity from sewage sludge. Bioresour. Technol. 2011, 102, 5602-5608.

(32) Gros, M.; Petrović, M.; Barceló, D. Tracing pharmaceutical residues of different therapeutic classes in environmental waters by using liquid chromatography/quadrupole-linear ion trap mass spectrometry and automated library searching. Anal. Chem. 2009, 81, 898-912.

(33) Font Segura, X.; Gabarrell Durany, X.; Ramos Lozano, D.; Vicent Huguet, T. Detoxification pretreatment of black liquor derived from non-wood feedstock with white-rot fungi. Environ. Technol. 1993, $14,681-687$.

(34) Jelić, A.; Petrović, M.; Barceló, D. Multi-residue method for trace level determination of pharmaceuticals in solid samples using pressurized liquid extraction followed by liquid chromatography/ quadrupole-linear ion trap mass spectrometry. Talanta 2009, 80, 363371.

(35) Kaal, E. E. J.; de Jong, E. D.; Field, J. A. Stimulation of ligninolytic peroxidase activity by nitrogen nutrients in the white rot fungus Bjerkandera sp. strain BOS55. Appl. Environ. Microbiol. 1993, 59, 4031-4036.

(36) Wariishi, H.; Valli, K.; Gold, M. H. Manganese (II) oxidation by manganese peroxidase from basidiomycete Phanerochaete chrysosporium. J. Biol. Chem. 1992, 267, 23688-23695.

(37) Rodríguez-Rodríguez, C. E.; Marco-Urrea, E.; Caminal, G. Naproxen degradation test to monitor Trametes versicolor activity in solid-state bioremediation processes. J. Hazard. Mater. 2010, 179, $1152-1155$.

(38) Weisburg, W. G.; Barns, S. M.; Pelletier, D. A.; Lane, D. J. 16S ribosomal DNA amplification for phylogenetic study. J. Bacteriol. 1991, 173, 697-703.

(39) Gardes, M.; Bruns, T. D. ITS primers with enhanced specificity for basidiomicetes - application to the identification of mycorrhizae and rusts. Mol. Ecol. 1993, 2, 113-118.

(40) White, T. J.; Bruns, T.; Lee, S.; Taylor, J. Amplification and direct sequencing of fungal ribossomal RNA genes for phylogenetics. In PCR Protocols; Innins, M. A., Gelfand, D. H., Sninsky, J. J., White, T. J., Eds.; Academic Press: San Diego, 1990; pp 315.

(41) Nübel, U.; Engelen, B.; Felske, A.; Snaidr, J.; Wieshuber, A.; Amann, R. I.; Ludwig, W.; Backhaus, H. Sequence heterogeneities of genes encoding $16 \mathrm{~S}$ rRNAs in Paenibacillus polymyxa detected by temperature gradient gel electrophoresis. J. Bacteriol. 1996, 178, 56365643.

(42) Hall, T. A. BioEdit: a user-friendly biological sequence alignment editor and analysis program for Windows 95/98/NT Nucl. Acids Symp. Ser 1999, 41, 95-98.

(43) Altschul, S. F.; Gish, W.; Miller, W.; Meyers, E. W.; Lipman, D. J. Basic local alignment search tool. J. Mol. Biol. 1990, 215, 403-410.

(44) Barajas-Aceves, M.; Hassan, M.; Tinoco, R.; Vazquez-Duhalt, R. Effect of pollutants on the ergosterol content as indicator of fungal biomass. J. Microbiol. Methods 2002, 5, 227-236.

(45) Cuenca-Estrella, M.; Gómez-López, A.; Mellado, E.; Buitrago, M. J.; Monzón, A.; Rodríguez-Tudela, J. L. Scopulariopsis brevicaulis, a fungal patogen resistant to broad-spectrum antifungal agents. Antimicrob. Agents Chemother. 2003, 47, 2339-2341.

(46) Summerbell, R. C.; Gueidan, C.; Schroers, H. J.; de Hoog, G. S.; Starink, M.; Arocha Rosete, Y.; Guarro, J.; Scott, J. A. Acremonium phylogenetic overview and revision of Gliomastix, Sarocladium, and Trichothecium. Stud. Mycol. 2011, 68, 139-162.
(47) Gugnani, H. C. Nondermatophytic filamentous keratinophilic fungi and their role in human infection. In Biology of Dermatophytes and Other Keratinophilic Fungi; Kushwaha, R. K. S., Guarro, J., Eds.; Revista Iberoamericana de Micología: Bilbao, 2000; pp 109.

(48) Chee-Sanford, J. C. Weed seeds as nutritional resources for soil Ascomycota and characterization of specific association between plant and fungal species. Biol. Fertil. Soils 2008, 44, 763-771.

(49) Nam, J. H.; Bae, W.; Lee, D. H. Oceanobacillus caeni sp. nov., isolated from a Bacillus-dominated wastewater treatment system in Korea. Int. J. Syst. Evol. Microbiol. 2008, 58, 1109-1113.

(50) Cerniglia, C. E. Fungal metabolism of polycyclic aromatic hydrocarbons: past, present and future application in bioremediation. J. Ind. Microbiol. Biotechnol. 1997, 19, 324-333.

(51) Marco-Urrea, E.; Pérez-Trujillo, M.; Vicent, T.; Caminal, G. Ability of white-rot fungi to remove selected pharmaceuticals and identification of degradation products of ibuprofen by Trametes versicolor. Chemosphere 2009, 74, 765-772.

(52) Tucker, B.; Radtke, C.; Kwon, S. I.; Andersson, A. J. Suppression of bioremediation by Phanerochaete chrysosporium by soil factors. J. Hazard. Mater. 1995, 41, 251-265.

(53) Mougin, C.; Pericaud, C.; Dubroca, J.; Asther, M. Enhanced mineralization of lindane in soils supplemented with the white rot basidiomycete Phanerochaete chrysosporium. Soil Biol. Biochem. 1997, 29, 1321-1324.

(54) Novotný, Č.; Erbanová, P.; Šašek, V.; Kubátová, A.; Cajthalm, T.; Lang, E.; Krahl, J.; Zadražil, F. Extracellular oxidative enzyme production and PAH removal in soil by exploratory mycelium of white rot fungi. Biodegradation 1999, 10, 159-168.

(55) Borràs, E.; Caminal, C.; Sarrà, M.; Novotný, Č. Effect of soil bacteria on the ability of polycyclic aromatic hydrocarbons (PAHs) removal by Trametes versicolor and Irpex lacteus from contaminated soil. Soil Biol Biochem. 2010, 42, 2087-2093.

(56) Rodríguez-Rodríguez, C. E.; Barón, E.; Gago-Ferrero, P.; Jelić, A.; Llorca, M.; Farré, M.; Díaz-Cruz, M. S.; Eljarrat, E.; Petrović, M.; Caminal, G.; Barceló, D.; Vicent, T. Removal of pharmaceuticals, polybrominated flame retardants and UV-filters from sludge by the fungus Trametes versicolor in bioslurry reactor. J. Hazard. Mater. 2012, 233-234, 235-243.

(57) Jelić, A.; Cruz-Morató, C.; Marco-Urrea, E.; Sarrà, M.; Pérez, S.; Vicent, T.; Petrović, M.; Barceló, D. Degradation of carbamazepine by Trametes versicolor in an air pulsed fluidized bed bioreactor and identification of intermediates. Water Res. 2012, 46, 955-964.

(58) Radtke, C.; Cook, W. S.; Andersson, A. Factors affecting antagonism of growth of Phanerochate chrysosporium by bacteria isolated from soils. Appl. Microbiol. Biotechnol. 1994, 41, 274-280.

(59) Carballa, M.; Omil, F.; Ternes, T.; Lema, J. M. Fate of pharmaceutical and personal care products (PPCPs) during anaerobic digestion of sewage sludge. Water Res. 2007, 41, 2139-2150.

(60) Wang, Q.; Garrity, G. M.; Tiedje, J. M.; Cole, J. R. Naive Bayesian classifier for rapid assignment of rRNA sequences into the new bacterial taxonomy. Appl. Environ. Microbiol. 2007, 73, 52615267. 